\title{
Diabetic autonomic neuropathy of the gastrointestinal tract
}

\author{
Edwin Kuźnik ${ }^{1}$, Robert Dudkowiak², Rajmund Adamiec ${ }^{1}$, Elżbieta Poniewierka ${ }^{3}$ \\ ${ }^{1}$ Department of Angiology, Hypertension and Diabetology, Wroclaw Medical University, Wroclaw, Poland \\ 2Dietetics Division, Department of Gastroenterology and Hepatology, Wroclaw Medical University, Wroclaw, Poland \\ ${ }^{3}$ Department of Gastroenterology and Hepatology, Wroclaw Medical University, Wroclaw, Poland
}

Gastroenterology Rev 2020; 15 (2): 89-93 DOI: https://doi.org/10.5114/pg.2020.95554

Key words: diabetes melitus, autonomic neuropathy, diabetic enteropathy, diabetic gastroparesis.

Address for correspondence: Dr Edwin Kuźnik, Department of Angiology, Hypertension and Diabetology, Wroclaw Medical University, Jan Mikulicz Radecki Clinical University Hospital, 213 Borowska St, 50-556 Wroclaw, Poland, e-mail: edvin@op.pl

\begin{abstract}
Diabetes is a metabolic disease leading to the development of numerous health complications. In developed countries, it is the main cause of blindness, end-stage renal disease, and non-traumatic amputation of the lower limbs. Neuropathy is the most common chronic complication of diabetes. A long-term course of a metabolically unbalanced disease causing damage to the autonomic nervous system of the digestive tract results in the development of many complications, such as intensification of gastro-oesophageal reflux disease, gastroparesis, chronic diarrhoea or faecal incontinence.
\end{abstract}

\section{Introduction}

Diabetes is the dominant civilization disease. According to data from the International Diabetes Federation (IDF), there are 451 million people in the world who live with diabetes, and the estimated number of patients in the year 2045 will amount to 693 million [1]. In Poland, the number of diabetics was set at 2.7 million, which is about $7 \%$ of the population [2]. Over $85 \%$ of cases are type 2 diabetes, associated with obesity and a western lifestyle. Less than $10 \%$ of patients are people with type 1 diabetes; they require perpetual insulin therapy, and the cause of the development of this form of the disease is still not entirely clear. The growing number of patients with diabetes has an epidemic character; therefore, actions are being taken to prevent the development of the disease and improve treatment outcomes. International Diabetes Day is celebrated annually on 14 November - the birthday of Frederick Banting, the co-discoverer of insulin.

Abnormal metabolic disease leads to complications such as macroangiopathy (arterial occlusive disease), as well as microvascular complications (e.g. retinopathy, nephropathy, neuropathy). Damage to the nerve fibres of the peripheral nervous system is the most common chronic complication of diabetes. The manifestation of clinical symptoms is dominated by distal symmetrical diabetic neuropathy (with effects on lower limbs, such as: paraesthesia, analgesia and thermoanaesthesia or the risk of developing diabetic foot syndrome) and autonomic neuropathy (herein primarily refers to cardiovascular and gastrointestinal neuropathy). Neuropathy of the gastrointestinal tract leads to development of numerous complications, such as: escalation of gastro-oesophageal reflux disease (GERD), gastroparesis, diarrhoea, habitual constipation and faecal incontinence. It is also worth mentioning that gut hormones play an important role in the pathogenesis of type 2 diabetes [3].

\section{Pathogenesis}

The correct function of the digestive tract depends on well-coordinated peristaltic movements. The motility of the digestive tract is regulated by nervous and endocrine systems and allows the proper passage of food until its extraction, under a person's full mind control. Looking at the microscopic structure of intestinal wall, we distinguish submucosal nerve plexuses (respectively, Meissner's internal and Schabadasch's external) and the Auerbachian muscular plexus. Submucosal bands are responsible for regulation of glandular secretion 
and contractility of lamina muscularis of the mucosa. However, the Auerbach's plexus, located between the layers of peripheral and longitudinal muscles, controls peristaltic movements [4]. The above-mentioned nerve fibres are connected with the central nervous system by the sensory (afferent) and efferent fibres of the autonomic sympathetic and parasympathetic systems. The entire nervous system managing intestinal functions is referred to as the central nervous system (CNS). In addition, interstitial cells of Cajal (ICC) are found along the entire length of the gastrointestinal tract, which spontaneously generate systolic stimuli [5]. Their function can be compared to pacemaker cells in the sinoatrial node of the heart. Thus, the digestive system, being under the control of the central nervous system, has considerable independence in regulating its motility. It seems that the amount of information sent to the CNS is much larger than that received; for example, in parasympathetic nerves, about $80 \%$ of nerve fibres are afferent [6].

In the course of metabolically unbalanced diabetes, there are many pathogenic pathways to intestinal dysfunction. Excessive glucose concentration in the blood results in its excessive absorption by glucose transporters (mainly GLUT-3) to cells. Inside cells, a properly metabolised glucose molecule is broken down into six molecules of water and carbon dioxide. This initially takes place by glycolysis in cytoplasm and then through the citric acid cycle and the respiratory chain within mitochondrion. With an excess of glucose, some of the molecules are metabolised through alternative pathways (e.g. polyol, hexosamine, methylglycine, diacylglycerol resynthesis). By attaching themselves to proteins or fats, the resulting molecules cause the formation of so-called advanced glycation end-products (AGEs) [6]. They cause damage to the structure of nerve cells and interfere with their function. It causes a reduction in the number of CNS neurons and ICC cells and damage to smooth muscle cells resulting in their decreased contractility. Neuropathy is also favoured by other pathogenic mechanisms, such as damage to small vessels supplying the nerves (i.e. vasa nervorum), osmotic stress, and inflammatory processes [7]. The above-mentioned disorders all cause impairment of the gastrointestinal tract.

The most common diseases to which gastrointestinal neuropathy leads include intensification of GERD, gastroparesis, diarrhoea, habitual constipation and faecal incontinence. In clinical practice, three principles must be borne in mind to associate specific complaints with diabetic autonomic neuropathy [8]. First, the diagnosis of neuropathy is in most cases a diagnosis of exclusion [9]; therefore, in most cases a differential diagnosis is crucial. Second, severe symptoms of neu- ropathy most commonly appear in patients with documented long-term lack of metabolic control. Advanced damage to autonomic nerve fibers is also uncommon in a person with newly diagnosed diabetes and target range value of glycated hemogobin. Third, the increased destruction of autonomic nerve fibres is usually accompanied by other complications, especially of the microangiopathy type (i.e. retinopathy, nephropathy). Naturally, even the optimal control of diabetes does not protect against development of neuropathy. What is interesting, optimal glycaemia significantly reduces the severity of already existing neuropathy in type 1 diabetes and significantly less in type 2 . Because of the fact that some part of autonomic nerve fibres is shared with those controlling the cardiovascular system, a significant percentage of patients show signs of neuropathy of this system as well; tachycardia, orthostatic hypotension, intolerance of physical activity and asymptomatic acute coronary syndromes are commonly observed. In addition, in examination of a patient it is worth paying attention to symptoms that may indicate distal symmetric polyneuropathy (DSPN), which is the most common form of polyneuropathy and is usually accompanied by other types of neuropathy. Among the symptoms of DSPN, there are a few specifically concerning feet: pain and temperature disturbances, deep sensory disturbances, paraesthesia (e.g. numbness, tingling, and formication). Due to disturbed sweat glands, the skin on foot and crus is dry and flaky.

\section{Severity of gastro-esophageal reflux disease}

GERD occurs due to reverse of acidic gastric contents into the oesophagus caused by malfunction of the lower oesophageal sphincter (LES). It is also known that periodic LES relaxation is a physiological phenomenon. We recognise GERD in the situation of destruction of the mucous membrane of the oesophagus or the nuisance of symptoms for the patient. The dominant symptom of the disease is heartburn. In developed countries, one in five people report symptoms typical of GERD as being present once a week. In the course of diabetes, the occurrence of disease symptoms is significantly more frequent. This is due to neuropathy, which reduces the lower tension of the oesophageal sphincter and delays emptying of the stomach. In the case of type 2 diabetes, an additional factor contributing to the severity of GERD symptoms is abdominal obesity. For patients with diagnosis of GERD oesophagogastroscopy should be reserved only for cases of resistance to treatment and the occurrence of extra-oesophageal symptoms; similarly, the qualification for $24 \mathrm{~h}$ ph-metry should proceed [10]. In principle, proton pump in- 
hibitors are used to treat symptoms of the disease. An important element of the procedure, especially in this group of patients, are non-pharmacological recommendations, which include: normalisation of body weight, avoidance of certain foods (e.g. coffee, alcohol, fried and roasted products), avoidance of horizontal position after meals, and sleeping with an elevated headrest [11].

\section{Diabetic gastroparesis}

Diabetic gastroparesis is the most common symptom attributed to vegetative neuropathy in the gastrointestinal tract. This is a disease resulting in delayed emptying of the stomach with absence of identifiable factors hindering the passage of food into the duodenum [12]. From the evolutionary point of view, the stomach can be treated as a food storage. Functionally, the stomach can be divided into two parts: proximal (i.e. bottom, upper part of the body) and distal (i.e. remaining part of the organ). The proximal part remains under constant systolic activity of the vagus nerve and can be treated as a storage for food. However, the task of the distal part is crushing and mixing food, and it remains under the control of the vegetative system with pacemaker cells located at the height of 2/3 of greater curvature of the stomach, generating spasms. An additional element controlling the operation of the stomach is the endocrine system (i.e. gastrin, secretin) [13]. It is expected that hyperglycaemia will inhibit gastric emptying and hypoglycaemia will have the opposite effect - the food from the stomach will eventually be absorbed and the glycaemia will rise. The secretion of insulin on the incretin axis will also increase [14]. While in physiological conditions this mechanism maximises the utilisation of a meal, it becomes a factor increasing symptoms of the disease in the presence of chronic hyperglycaemia. The most common ailments in the course of gastroparesis are: dyspepsia, bloating, epigastric fullness and pain, but nausea and vomiting may also appear [15]. The incidence of clinically significant gastroparesis is estimated at less than $10 \%$ of people with diabetes. From the patient's point of view, gastroparesis has far-reaching therapeutic consequences: the absorption of oral medications is delayed, and in the case of insulin therapy the use of prandial analogues of rapid-acting insulins may lead to episodes of hypoglycaemia. Ultrasound diagnosis (i.e. evaluation of emptying after taking liquid meals), X-ray (i.e. pronouncing gastric dilation), manometry and electrogastrography (mainly in clinical centres) are used in diagnosis of the disease. The treatment with prokinetic prokinetic drugs (e.g. metoclopramide, itopride, trimebutine, STW 5 herbal preparation) should be only short-term, due to the side effects of some. It is recommended that patients follow a low-fibre and low- fat diet, preferably semi-liquid meals divided in small portions. It is necessary to avoid chewing gum and drinking carbonated beverages. In addition, when this complication occurs, the use of incretin drugs in therapy of diabetes (i.e. GLP-1 analogues and DPP-4 inhibitors) should be discontinued. In insulin therapy, it is recommended to replace insulin analogues with short-acting human insulin given about $30 \mathrm{~min}$ before a meal [16].

\section{Small intestinal bacterial overgrowth syndrome (SIBO)}

$\mathrm{SIBO}$ is a disorder of excessive proliferation in the jejunum of bacterial flora from the large intestine. No significant number of bacteria are found in the jejunum under physiological conditions. The relative sterility of the small intestine is ensured by: bactericidal action of gastric and pancreatic juice, immunoglobulin A mucosa inhibiting adherence of bacterial cells, peristaltic movements of the small intestine moving the food content in the direction of the large intestine, and the presence of the ileocecal valve. The occurrence of SIBO in patients with diabetes is estimated at over $50 \%$. In pathogenesis disorders of the small intestine peristalsis are mainly considered [17]. SIBO can be increased by the damage to pancreatic parenchyma in the course of type 3 diabetes (i.e. decreased production of pancreatic juice) as well as increased $\mathrm{pH}$ of gastric juice due to the longterm use of proton pump inhibitors in obese patients with type 2 diabetes. Symptoms of SIBO result from the damage to intestinal villi, vitamin $B_{12}$ deficiency (which is used by bacteria), and digestive disorder of fats and absorption of fat-soluble vitamins. Therefore, patients may experience bloating, abdominal pain, fatty diarrhoea, and symptoms of vitamin A, D, E, and $B_{12}$ deficiency. The suggested treatment is primarily based on antibiotic therapy (e.g. metronidazole, rifaximin) and a diet with the restriction of products with high fermentation potential (low FODMAP) [18].

\section{Diarrhoea}

Diarrhoea means passing at least three stools of a liquid or semi-fluid consistency, in the course of one day. In chronic diabetes diarrhoea is observed in approximately $20 \%$ of patients [19]. Mechanisms of the occurrence of diarrhoea are very different. In case of neuropathy, disturbances of intestinal peristalsis or disturbances in water and electrolyte transport are observed, which results in watery diarrhoea [20]. However, it should be remembered that diarrhoea caused by diabetes usually has a non-neuropathic aetiology. The diagnosis should include: the possibility of co-association with coeliac disease and type 1 diabetes (in about $5 \%$ of patients), drug-induced aetiology (in most 
cases caused by metformin intake - the usual solution is a simple change to another manufacturer's product), damage to the pancreatic parenchyma in the course of type 3 diabetes (fatigue is typical in this case, taking into account the unstable course of the disease and the frequent problem of alcoholism resulting in failure to comply with recommendations, this group of patients has the worst prognosis) and SIBO coexistence [18]. Treatment of diarrhoea will depend on its aetiology. Neuropathic forms may require the use of loperamide or smecta. Coeliac disease requires a gluten-free diet [21]. Type 3 diabetes requires supplementation of pancreatic enzymes.

\section{Faecal incontinence}

Faecal incontinence means the loss of conscious control over the passing of stools. Some authors add to the definition the loss of control over gas emission [22]. As an embarrassing disorder, it is often hidden from medical staff. Faecal incontinence may be caused by neuropathy resulting in abnormal functioning of the internal and external anal sphincter, anorectal reflexes, and motor-sensory dysfunction of the rectum [23]. The diagnosis is based on anorectal manometry (it allows the assessment of anal sphincter function) or defecography (a test used mostly in the past). Diapers and short-term antidiarrhoeal medications are used in the treatment [24].

\section{Postprandial orthostatic hypotension}

Orthostatic hypotension is a classic symptom of vegetative neuropathy of the cardiovascular system. Due to the disturbance of the baroreceptor reflexes and disturbances in the tension of blood vessel walls, a significant drop in blood pressure occurs when taking a standing position. In the course of diabetes, the consumption of a rich meal becomes a stimulus with the very same effect as standing up [25]. This results in a significantly high inflow of blood to the visceral circulation and leads to hypotonic symptoms, due to impaired control of peripheral resistance and cardiac output regulation. The blood flow through the visceral circulation may be as plentiful as $1 / 4$ of the cardiac output, i.e., about $1500 \mathrm{ml} / \mathrm{min}$, of which $1000 \mathrm{ml}$ falls into the portal vein. In addition, visceral veins are a significant reservoir of circulating blood; therefore, such large fluctuations in the distribution of circulating blood require the correct function of a vegetative system that allows maintenance of a constant blood pressure. With hypotension, the patient may report dizziness, the presence of scotoma, and in extreme cases fainting may occur as well. This form of hypotension seems to be treated in the best way by eating meals divided into small portions. Improvement may be brought by use of drugs reducing gastric emptying [26].

\section{Summary}

The clinical manifestation of disorders observed in the course of diabetic neuropathy of the gastrointestinal tract is very broad. Differently conducted diagnoses have various levels of complexity. Recommended treatment is specific to the reported ailments. However, it should be remembered that the possibilities of causal treatment are limited. The first and the most important method of treatment of gastrointestinal neuropathy is still the correct metabolic control of diabetes.

\section{Conflict of interest}

The authors declare no conflict of interest.

\section{References}

1. Cho NH, Shaw JE, Karuranga S, et al. IDF Diabetes Atlas: Global estimates of diabetes prevalence for 2017 and projections for 2045. Diabetes Res Clin Pract 2018; 138: 271-81.

2. Topor Madry R, Wojtyniak B, Strojek K, et al. Prevalence of diabetes in Poland: a combined analysis of national databases. Diabet Med 2019; 36: 1209-16.

3. Adamska E, Ostrowska L, Górska M, Krętowski A. The role of gastrointestinal hormones in the pathogenesis of obesity and type 2 diabetes. Gastroenterol Rev 2014; 9: 69-76.

4. Scheuermann DW, Stach W, Timmermans JP. Topography, architecture and structure of the plexus submucosus externus (Schabadasch) of the porcine small intestine in scanning electron microscopy. Acta Anat 1987; 129: 105-15.

5. Horváth VJ, Putz Z, Izbéki F, et al. Diabetes-related dysfunction of the small intestine and the colon: focus on motility. Curr Diab Rep 2015; 15: 94.

6. Meldgaard T, Olesen SS, Farmer AD, et al. Diabetic enteropathy: from molecule to mechanism-based treatment. J Diabetes Res 2018; 2018: 3827301.

7. Yarandi SS, Srinivasan S. Diabetic gastrointestinal motility disorders and the role of enteric nervous system: current status and future directions. Neurogastroenterol Motil 2014; 26 : 611-24.

8. Poniewierka E, Dębiński P, Krywejko J. Alimentary tract disorders in diabetes. Fam Med Prim Care Rev 2006; 8: 95-101.

9. Pop-Busui R, Boulton AJM, Feldman EL, et al. Diabetic neuropathy: a position statement by the American Diabetes Association. Diabetes Care 2017; 40: 136-54.

10. Franek E. Leczenie powikłań cukrzycy i chorób z nią wspótistniejących. Wydawnictwo San Rogue, 2018; 235-45.

11. Dudkowiak R, Poniewierka E. The role of diet and life style in the treatment of gastroesophageal reflux disease. Fam Med Prim Care Rev 2012; 14: 586-91.

12. Siraj ES, Homko C, Wilson LA, et al. Islet cell associated autoantibodies and c-peptide levels in patients with diabetes and symptoms of gastroparesis. Front Endocrinol 2018; 9: 32. 
13. Aswath GS, Foris LA, Patel K. Diabetic Gastroparesis In Stat Pearls. Treasure Island (FL): Stat Pearls Publishing 2019.

14. Stephens JW. The incretin system in the management of type 2 diabetes mellitus. Clin Med 2010; 10: 491-5.

15. Tack J, Carbone F, Rotondo A. Gastroparesis. Curr Opin Gastroenterol 2015; 31: 499-505.

16. Krzyżewska M, Maroszek P, Mrozikiewicz-Rakowska B, et al. Gastropareza cukrzycowa: czy wiesz, jak ją rozpoznać oraz skutecznie leczyć? Clin Diabetol 2014; 3: 157-66.

17. Ojetti V, Pitocco D, Scarpellini E, et al. Small bowel bacterial overgrowth and type 1 diabetes. Eur Rev Med Pharmacol Sci 2009; 13: 419-23.

18. Gotfried J, Priest S, Schey R. Diabetes and the small intestine. Curr Treat Options Gastroenterol 2017; 15: 490-507.

19. Frías Ordoñez JS, Otero Regino W. Chronic diarrhea in the diabetic. A review of the literature. Rev Gastroenterol Peru 2016; 36: 340-9.

20. Careyva B, Stello B. Diabetes mellitus: management of gastrointestinal complications. Am Fam Physician 2016; 94: 980-6.

21. Kylökäs A, Kaukinen K, Huhtala H, et al. Type 1 and type 2 diabetes in celiac disease: prevalence and effect on clinical and histological presentation. BMC Gastroenterol 2016; 16: 76.

22. Alavi K, Chan S, Wise P, et al. Fecal incontinence: etiology, diagnosis, and management. J Gastrointest Surg 2015; 19: 1910-21.

23. Reszczyńska M, Marczak-Karpina B. Dysfunction of the lower gastrointestinal tract as a complication of diabetes - a problematic issue in the diabetic care. Clin Diabetol 2016; 5: 95-9.

24. Maisey A. A practical approach to gastrointestinal complications of diabetes. Diabetes Ther 2016; 7: 379-86.

25. Solini A, Grossman E. What should be the target blood pressure in elderly patients with diabetes? Diabetes Care 2016; 39 (Suppl. 2): S234-43.

26. Saito Y, Ishikawa J, Harada K. Postprandial and orthostatic hypotension treated by sitagliptin in a patient with dementia with Lewy Bodies. Am J Case Rep 2016; 17: 887-93.

Received: 28.03.2019

Accepted: 2.04.2019 